\title{
Solution for Optimal Power Flow Problem Using WDO Algorithm
}

\author{
Ranjani Senthilkumar ${ }^{a}$, Karimulla P Sk ${ }^{b}$, K.B.V.S.R. Subrahmanyam ${ }^{\mathrm{c}}$ and Ram Deshmukh \\ A Department of Electrical and Electronics Engineering, Saveetha School of Engineering, SIMATS, Chennai, India. \\ B Department of Electrical and Electronics Engineering, Malla Reddy college of engineering and technology, Hyderabad, \\ India. \\ C Department of Electrical and Electronics Engineering, S R Engineering College, Warangal, India \\ d Department of Electrical and Electronics Engineering, S R Engineering College, Warangal, India
}

Article History: Received: 11 January 2021; Accepted: 27 February 2021; Published online: 5 April 2021

\begin{abstract}
Wind driven optimization (WDO) algorithm is a best optimization method based on atmospherically motion, global optimization nature inspired method. The method is based on population iterative analytical global optimization for multifaceted and multi prototype in the search domain for constraints to implement. In this paper, WDO algorithm is accustomed to find optimal power flow solution. To find the efficacy of the technique, it is applied to IEEE 30 bus systems to find fuel cost for generation of power as a main objective. Obtained results were compared with other techniques shows the better solution for optimal power flow problem.
\end{abstract}

Keywords: Wind driven optimization (wdo) algorithm, fuel cost for generation, optimal power flow solution.

\section{Introduction}

For power system control and functioning, optimal power flow solution is back bone (R.B., 1961; Bhasha, 2020). Optimizing and optimal operating in a satisfying operating constrains is main objective of optimal power flow problem.

Over a half of s century optimal power flow problem studied. There were many deterministically optimization method has successfully implemented. Some are gradient based technique sequential quadratic type algorithm; Newton based methods and interior point method. Optimality and grow with come theoretical suppositions like convexity, complexity and other are not suitable for optimal power flow condition. A survey for commonly used methods is given in (Huneault , 1991; ChinnamahammadBhasha, 2020). Many of the optimization methods are mostly used in industrial applications and have some short falls (Balamurugan, 2020). There are so many drawbacks with these methods. Some of them are; they are not able to handle integer variables or binary they cannot global (ChinnamahammadBhasha, 2020; Deepthi, 2019; Aroulanandam, 2020). Nowadays, rapid growth in computational tools has boosted investigation in area of nondeterministic that is 'heuristic' methods used to work out the optimization problems in last two decades are Biogeography based optimization (BBO),bacterial foraging algorithm (BFA), Artificial neutral network(ANN), Ant colony algorithm (ACA), differential evaluation (DE), particle swarm optimization (PSO),algorithm of chaos, evolutionary algorithm, evolutionary programming methods, evolution strategies (ES), gravitational search algorithm (GSA) (ChinnamahammadBhasha, 2020; Balamurugan, 2020), Tabu search (TS), for finding optimal solutions and avoided to be confine with local one these methods are known for capabilities, quick search of large solutions and their capacity to uncertainty in area of power systems (Balamurugan, 2020). A brief review on optimal power flow solution using optimization methods is given in (Frank, 2012; Karimulla, 2019; Garikapati, 2020; Latchoumi, 2020; Pavan, 2020).

WDO is the recently developed optimization method, and nature inspired optimization method. It has been proved that WDO is uncomplicated and successful in performing multifaceted optimization problems. The aim of this article is to find solution for optimal power flow problem using WDO method. Under the objective of generation fuel cost minimization, performance of WDO is tested and sought on IEEE-30 bus stranded test system.

In this paper first OPF is mathematically evaluated after that WDO is presented. To solve optimization issue the power operating constraints WDO method is used at last concluded with important points.

\section{Optimal Power Flow}

The non linear mathematical representation can be given the form of formulae as

$$
\begin{aligned}
& \text { Minimize } \mathrm{f}(\mathrm{x}, \mathrm{u}) \\
& \text { Subjected to } \mathrm{g}(\mathrm{x}, \mathrm{u})=0 \\
& \mathrm{~h}(\mathrm{x}, \mathrm{u}) \leq 0
\end{aligned}
$$

\subsection{Fuel cost objective}


The simple quadratic cost equation for $\mathrm{i}^{\text {th }}$ unit for active power is given as

$$
\mathrm{F}\left(\mathrm{P}_{\mathrm{Gi}}\right)=\mathrm{A}_{\mathrm{i}} \mathrm{P}_{\mathrm{Gi}}{ }^{2}+\mathrm{B}_{\mathrm{i}} \mathrm{P}_{\mathrm{Gi}}+\mathrm{C}_{\mathrm{i}}
$$

Where $A_{i}, B_{i}$ and $C_{i}$ are generators coefficients for fuel cost . Fuel cost generation Ft of all generators (Ng) can calculate using the expression

$$
\mathrm{A}_{1}=\min (\mathrm{Ft})=\sum_{i=1}^{\mathrm{N}_{\mathrm{g}}} \mathrm{f}_{\mathrm{i}}\left(\mathrm{P}_{\mathrm{Gi}}\right)
$$

It must be satisfy the inequality as well as equality constrains while minimizing fuel cost and constraints can be given in equation form as:

\subsubsection{Equality constraints are:}

The constraints are load flow expressions which are solved in conventional load flow procedure. Balance expressions for active, reactive powers in load flow are:

$$
\begin{aligned}
& \mathrm{P}_{\mathrm{Gi}}-\mathrm{P}_{\mathrm{Di}}=\sum_{j=1}^{N_{\text {bus }}}\left|\mathrm{V}_{\mathrm{i}}\right|\left|\mathrm{v}_{\mathrm{j}}\right|\left|\mathrm{Y}_{\mathrm{ij}}\right| \cos \left(\theta_{\mathrm{ij}}+\delta_{\mathrm{j}}-\delta_{\mathrm{i}}\right) \\
& \mathrm{Q}_{\mathrm{Gi}}-\mathrm{Q}_{\mathrm{Di}}=\sum_{j=1}^{N_{b u s}}\left|\mathrm{~V}_{\mathrm{i}}\right|\left|\mathrm{v}_{\mathrm{j}}\right|\left|\mathrm{Y}_{\mathrm{ij}}\right| \cos \left(\theta_{\mathrm{ij}}+\delta_{\mathrm{j}}-\delta_{\mathrm{i}}\right)
\end{aligned}
$$

Where $\mathrm{P}_{\mathrm{Gi}}, \mathrm{P}_{\mathrm{Di}} \mathrm{Q}_{\mathrm{G}}$ and $\mathrm{Q}_{\mathrm{Di}}$ are active and reactive power generation and demand at $\mathrm{i}^{\text {th }}$ bus .

$\mathrm{N}_{\text {bus }}$ is total number of buses, $\theta_{\mathrm{ij}}$ is phase angle difference, $\mathrm{Y}_{\mathrm{ij}}$ is the admittance magnitude connected between bus $i^{\text {th }}$ and $j^{\text {th }}$

\subsection{Inequality constraints are:}

\subsubsection{Generator constraints:}

$$
\begin{aligned}
& V_{G i}^{\min } \leq V_{G i} \leq V_{G i}^{\max } ; \quad \forall \mathrm{i} \in \mathrm{N}_{\mathrm{G}} \\
& P_{G i}^{\min } \leq P_{G i} \leq P_{G i}^{\max } ; \quad \forall \mathrm{i} \in \mathrm{N}_{\mathrm{G}} \\
& Q_{G i}^{\min } \leq Q_{G i} \leq Q_{G i}^{\max } ; \quad \forall \mathrm{i} \in \mathrm{N}_{\mathrm{G}}
\end{aligned}
$$

The other constraints are, tap setting transformer tap setting

$$
T_{i}^{\text {min }} \leq T_{i} \leq T_{i}^{\max } \quad \forall \mathrm{i} \in \mathrm{N}_{\mathrm{G}}
$$

Compensation limit of reactive power by shunt compensator:

$$
Q_{\text {shu }}^{\min } \leq Q_{\text {shu }} \leq Q_{\text {shu }}^{\max } \quad \forall \mathrm{i} \in \mathrm{N}_{\mathrm{G}}
$$

\subsubsection{Security constraints are:}

Voltage value constraint at load buses loadings at transmission lines are comes under security constrains. Every load bus voltage can be constricted within its upper and lower operating limits. The constraints can be given in equation form as:

$$
\begin{gathered}
\mathrm{S}_{1 \mathrm{i}} \leq S_{1 i}^{\max } \mathrm{I} \in \mathrm{N}_{\mathrm{L}} \\
V_{i}^{\text {min }} \leq V_{i} \leq V_{i}^{\text {max }} ; \quad \forall \mathrm{i} \in \mathrm{N}_{\mathrm{L}}
\end{gathered}
$$

Here $T_{i}, V_{G}, P_{G}$ and $Q_{\text {shu }}$ are self restricted inequality constraints and can be satisfied with in load flow problem, remaining three constrains along with active power are the non-self-restricted inequality constraints can operated by penalty approach (Ahrens, 2007). By this generalized load flow problem can be expressed as

$$
\begin{aligned}
J_{\text {aug }}(x, u)=J(x, u)+ & R_{p}\left(P_{G_{1}}-P_{G_{1}}^{\text {limit }}\right)^{2}+R_{v} \sum_{m=1}^{N L}\left(V_{m}-V_{m}^{\text {limit }}\right)^{2} \\
& +R_{q} \sum_{m=1}^{N G}\left(Q_{G_{m}}-Q_{G_{m}}^{\text {limit }}\right)^{2}+R_{s} \sum_{m=1}^{n l}\left(S_{l_{m}}-S_{l_{m}}^{\max }\right)^{2}
\end{aligned}
$$

Here $R_{P}, R_{V}, R_{q}, R_{s}$ are penalty factors and the limits are given as 


$$
x^{\text {limit }}=\left\{\begin{array}{cl}
x^{\max } ; & x>x^{\max } \\
x^{\min } ; & x<x^{\min }
\end{array}\right.
$$

$\mathrm{x}$ is value of $\mathrm{P}_{\mathrm{G}}, \mathrm{Q}_{\mathrm{Gm}}$, and $\mathrm{V}_{\mathrm{m}}$

\section{Wind Driven Optimization (Wdo) Algorithm:}

WDO algorithm is best optimization method based on atmospherically motion, and is global optimization nature inspired method. It is observed that wind driven optimization method is uncomplicated and successful in solving multifaceted optimization problems. The method is best suitable for population build heuristic iterative global optimization technique for multimodel and multifaceted search domain to implement different constraints. When compared with other iterative methods in WDO method, updated velocity equations, carioles and gravitational forces used to provide degree of freedom and robustness for fine tune. With the help of algorithm we can easily explain the WDO as:

Step 1: initialize max no. of iterations and population size.

Step 2: Assign the boundaries, pressure function and coefficients

Step 3: Assign velocity and random position

Step 4: Calculate pressure for all air parcels

Step 5: update velocity

Step 6: check velocity limits.

Step 7: update position and check boundaries

Step 8: repeat the steps i.e.4,5,6 and 7 until number iterations reached.

Step 8: display the result.

\subsection{Mathematical approach for WDO:}

Wind blows in atmosphere to make air pressure uniform, we know that air always moves to low pressure from a high pressure at some velocity, and proportional to pressure gradient (Bayraktar, 2010). Further in WDO some assumptions and simplified formulae which are derived from basic fundamentals are used. The starting step of WDO is based on Newton's $2^{\text {nd }}$ law, issued to find accurate result for examination of atmospheric motion (Robinson, 2004; Sampathkumar, 2020; Sampathkumar, 2020 ).

$$
\rho \vec{a}=\sum \overrightarrow{F_{l}}
$$

Here $\mathrm{F}_{1}$ is density of air, $\vec{a}$ acceleration vector $\mathrm{F}_{\mathrm{i}}$ is the forces acting on mass.

Ideal gas law gives the relation between air density, acceleration vector and temperature is given as below:

$$
\mathrm{P}=\mathrm{Rt}
$$

Here $\mathrm{P}, \mathrm{R}$ and $\mathrm{t}$ are pressure, universal gas constant and temperature.

In equation 9 there are fore forces, which cause te wind to move in particular direction and deflect its path. Noticeable force give rise to air in pressure gradient force $\left(\mathrm{F}_{\mathrm{pg}}\right)$, frictional force $\left(\mathrm{F}_{\mathrm{f}}\right)$ acts to opposite motion as described in equation 14. Gravitational force $\left(\mathrm{F}_{\mathrm{g}}\right)$ is acts in a vertical direction in three dimensional atmosphere when a $\mathrm{N}$ dimensional space mapped with it. Coriolis force $\left(\mathrm{F}_{\mathrm{c}}\right)$ caused by movement of earth, and averts path of wind. In this algorithm a motion in one direction that effect in another is implemented (Baraktar et al. 2010).

The equations for the above mentioned forces is given by

$$
\begin{aligned}
& \overrightarrow{F_{p g}}=-\Delta \rho \delta \mathrm{V} \\
& \overrightarrow{F_{g}}=\delta \rho V \vec{G} \\
& \overrightarrow{F_{c}}=-2 \vec{u} * \Omega
\end{aligned}
$$




$$
\overrightarrow{F_{f}}=-\vec{u} \rho \alpha
$$

Here $\Delta \rho$ : Represents pressure gradient, $\delta \mathrm{V}$ : is a inappreciable air volume, $\Omega$ : is movement of earth, $\mathrm{G}$ : Represents gravitational acceleration and $\mathrm{u}$ is wind velocity vector. Addition of all forces is given in equation 15

$$
\rho \vec{u} \Delta t=\delta \rho V \vec{G}+(-2 \vec{u} * \Omega)+(-\vec{u} \rho \alpha)+(-\Delta \rho \delta \mathrm{V})
$$

Assume an inappreciable air parcel moving with the velocity update expression which is given by equation number 16. From ideal gas equation from $(10), \rho$ in pressure, and a step unit time $(\Delta t=01)$ assumed for simplicity. Updated equation for velocity id given as:

$$
\begin{gathered}
\overrightarrow{u_{\text {new }}}=\left((1-\alpha) \overrightarrow{\left.u_{\text {old }}\right)}+g\left(-\overrightarrow{x_{\text {old }}}\right)+\right. \\
{\left[1 *\left|\left(\frac{P_{\text {max }}}{P_{\text {old }}}\right)-1\right| R t\left(x_{\max }-x_{\text {old }}\right)\right]+\left[-\frac{C_{\text {old }}^{\text {other dim }}}{P_{\text {old }}}\right](16)}
\end{gathered}
$$

From equation 16 we can observe that updated velocity value $\mathrm{u}_{\text {new }}$ depends on the previous iteration value uold.

The fitness value in genetic algorithm (GA) is analogous to pressure term in wind driven optimization technique. If it is compared with particle swam optimization (PSO) same updated velocity equation can be perceive. Once velocity is updated site of air parcel also should update as:

$$
\overrightarrow{x_{\text {new }}}=\overrightarrow{x_{\text {old }}}+\overrightarrow{u_{\text {new }}} * \Delta \mathrm{t}
$$

In equation 17 , we know that air parcel continue to move from one position to another creates friction. $\Delta t$ Is force of maximal pressure that is the global best site for optimization. Like this WDO is simple and successful to solve the multifaceted complex problems. WDO allows air parcel to move within the boundary of [-01, 01]. There are various boundary conditions presented in particle based optimization (Abido, 2002). Every air parcel influenced by gravitational force, are brought to boundaries back into search space. It is also being noted that per iteration for air parcels updated velocities are restricted. It avoids the air parcels to take number of steps and over looking in search space. Velocity dimension is restricted by its limits and is given by the equation 18 .

$$
\begin{aligned}
& u_{\text {new }}^{*}= u_{\max } \text { if } u_{\text {new }}>u_{\max } \\
& u_{\text {new }}^{*}=-u_{\max } \text { if } u_{\text {new }}<u_{\max }
\end{aligned}
$$

$\mathrm{u}_{\max }$ is adjusted velocity after, restricted to high speed.

\section{Results}

In order to check the WDO method, it has applied on IEEE 30 bus stranded test system. Program is developed in MATLAB software environment. IEEE 30 bus test system includes of six generator buses located at buses $1,11,2,8,5$, and 13 , four off nominal tap changing transformers with tap ratios at lines28-27,6-10, 6-9,412 , and and it also consists of nine shunt VAR compensators located at bus numbers $10,12,15,17,20,21,23,24$, and 29 (Lee, 1985; Abou, 2010) . Minimum and maximum boundaries, generator data, bus data and line data are available in (Bouchekara, 2013). By taking fuel cost for generator as an objective function proposed WDO algorithm is tested for OPF problem.

The WDO method is run for OPF and optimal solution obtained is tabulated in table 1. It has been observed that total fuel cost for generation is minimized as compared with other method. It is observed that generator fuel cost is reduced from $901.9416 \$ / \mathrm{h}$ to $799.069 \$ / \mathrm{h}$ which is almost $11.39 \%$.

Under same constraints i.e. system data control variable limits results obtained from WDO is compared with other methods as given in literature.

Table 2 gives clear comparison of WDO with other methods. It has proved that proposed method is best, uncomplicated and successful method to solve multifaceted problems. 
Table 1. Optimal setting of control variables

\begin{tabular}{|c|c|c|c|c|}
\hline Control Variables & Min & Max & Optimal power flow & Normal Load flow \\
\hline V1 & 0.95 & 1.1 & 1.1000 & 1.050 \\
\hline $\mathbf{V 2}$ & 0.95 & 1.1 & 1.0878 & 1.040 \\
\hline V5 & 0.95 & 1.1 & 1.0617 & 1.010 \\
\hline V8 & 0.95 & 1.1 & 1.0694 & 1.010 \\
\hline V11 & 0.95 & 1.1 & 1.1000 & 1.050 \\
\hline V13 & 0.95 & 1.1 & 1.1000 & 1.050 \\
\hline P1 & 50 & 200 & 177.0578 & 99.223 \\
\hline $\mathbf{P 2}$ & 20 & 80 & 48.6973 & 80.000 \\
\hline P5 & 15 & 50 & 21.3044 & 50.000 \\
\hline P8 & 10 & 35 & 21.0811 & 20.000 \\
\hline P11 & 10 & 30 & 11.8843 & 20.000 \\
\hline P13 & 12 & 40 & 12.0000 & 20.000 \\
\hline T11(6-9) & 0.9 & 1.1 & 1.0447 & 1.078 \\
\hline T11(6-10 & 0.9 & 1.1 & 0.9000 & 1.069 \\
\hline T11(4-12) & 0.9 & 1.1 & 0.9863 & 1.032 \\
\hline T11(28-27) & 0.9 & 1.1 & 0.9657 & 1.068 \\
\hline QC10 & 0 & 5 & 0.0000 & 0.000 \\
\hline QC12 & 0 & 5 & 0.0000 & 0.000 \\
\hline QC15 & 0 & 5 & 0.0000 & 0.000 \\
\hline QC17 & 0 & 5 & 0.0000 & 0.000 \\
\hline QC20 & 0 & 5 & 0.0000 & 0.000 \\
\hline QC21 & 0 & 5 & 0.0000 & 0.000 \\
\hline QC23 & 0 & 5 & 0.0000 & 0.000 \\
\hline QC24 & 0 & 5 & 0.0000 & 0.000 \\
\hline QC29 & 0 & 5 & 0.0000 & 0.000 \\
\hline $\begin{array}{l}\text { Generation fuel cost } \\
(\$ / \mathbf{h})\end{array}$ & - & - & 799.0691 & 901.952 \\
\hline
\end{tabular}

Table 2. Results Comparison

\begin{tabular}{|c|c|}
\hline Methods & Generation fuel cost(\$/h) \\
\hline Wind driven optimization technique & 799.0695 \\
\hline Gravitational Search Algorithm[16] & 798.6751 \\
\hline Differential Search Algorithm[15] & 799.0943 \\
\hline Differential Evolution[14] & 799.2891 \\
\hline Particle swarm optimization[17] & 800.96 \\
\hline Genetic algorithm[18] & 805.94 \\
\hline
\end{tabular}

\section{Conclusion}

In this paper, novel method is proposed to solve OPF issue in power systems that are Wind driven optimization method. : WDO algorithm is best optimization method based on atmospherically motion, and it is global optimization nature inspired method. On a IEEE 30 bus system WDO has been effectively and successfully applied, by considering minimization generation fuel cost as objective function. This paper is highly significant among the others for the following reasons

i) High ranking when compared with other techniques

ii) Efficacy and simple method

Efficiency of the WDO is proved by carried out analysis that has strength by converging optimal value is very close to it. 


\section{References}

1. Aroulanandam VV, Latchoumi TP, Balamurugan K, Yookesh TL. (2020) Improving the Energy Efficiency in Mobile Ad-Hoc Network Using Learning-Based Routing, Revue d'Intelligence Artificielle, Vol 34(3), pp. 337-343, 2020.

2. Bhasha, A.C., Balamurugan, K. (2020) End mill studies on Al6061 hybrid composite prepared by ultrasonic-assisted stir casting. Multiscale and Multidiscip. Model. Exp. and Design, https://doi.org/10.1007/s41939-020-00083-1

3. Balamurugan K. (2020) Metrological changes in surface profile, chip, and temperature on end milling of M2HSS die steel. International Journal of Machining and Machinability of Materials, 22(6):pp. 443-453.

4. Balamurugan K and Uthayakumar M, (2017) Preparation And Machining Studies Of Lapo4 Y2o3 Ceramic Matrix Composite, http://hdl.handle.net/10603/166221.

5. Balamurugan K, Uthayakumar M, Sankar S, Hareesh US, Warrier KG. (2020) Process optimisation and exhibiting correlation in the exploitable variable of AWJM. International Journal of Materials and Product Technology, 61(1), pp.16-33.

6. Chinnamahammad bhasha A, and Balamurugan, K. (2020) Fracture analysis of fuselage wing joint developed by aerodynamic structural materials." Materials Today: Proceedings, Vol.38, pp. 2555-2562.

7. ChinnamahammadBhasha, A., Balamurugan, K. (2020) Studies on Al6061nanohybrid Composites Reinforced with SiO2/3x\% of TiC -a Agro-Waste. Silico,. https://doi.org/10.1007/s12633-020-00758-x

8. Chinnamahammad Bhasha and Balamurugan K, (2020) Multi-objective optimization of high-speed end milling on Al6061/3\% RHA/ 6\% TiC reinforced hybrid composite using Taguchi coupled GRA, International Conference on Computational Intelligence for Smart Power System and Sustainable Energy (CISPSSE), Keonjhar, India, 2020, pp. 16, doi: 10.1109/CISPSSE49931.2020.9212295.

9. Deepthi T, and Balamurugan K. (2019) Effect of Yttrium (20\%) doping on mechanical properties of rare earth nano lanthanum phosphate (LaPO4) synthesized by aqueous sol-gel process. Ceramics International. 45(15), pp.18229-18235.

10. Garikapati P, Balamurugan K, Latchoumi TP, Malkapuram R. (2020) A Cluster-Profile Comparative Study on Machining AlSi $7 / 63 \%$ of SiC Hybrid Composite Using Agglomerative Hierarchical Clustering and K-Means. Silicon. https://doi.org/10.1007/s12633-020-00447-9

11. Karimulla Peerla Shaik, Dr. Venkata Prasanth, B., Dr. Rao, R.S (2017) Optimal Siting of UPFC using improved wind driven optimization algorithm", Journal of Advanced Research in Dynamical and Control Systems, 9 (14): :1881-1889.

12. Karimulla Peerla Shaik, Dr. Venkata Prasanth, B., Dr. Rao, R.S. (2019)Loadability Enhancement using Improved Wind Driven Optimization Algorithm" Journal of Green Engineering (JGE), 9 (3) :379-386.

13. Karimulla P Sk, Dr. Venkata Prasanth, B., Dr. Rao, R.S. (2019)A novel approach to solve optimal power flow problem" International Information and Engineering technology Association, 74(2-4) : 108-110.

14. Lee, K., Park, Y., Ortiz, J. (1985) A united approach to optimal real and reactive power dispatch IEEE Trans. Power App. Syst. 104 (5):1147-1153.

15. Latchoumi TP, Reddy MS, Balamurugan K. (2020) Applied Machine Learning Predictive Analytics to SQL Injection Attack Detection and Prevention. European Journal of Molecular \& Clinical Medicine.;7(02), pp. 3543-3553.

16. Niknam, T., RNarimani, M., Jabbari, M., Malekpour, A.R. (2011) A modified shuffle frogleaping algorithms for multi-objective optimal-power flowEnergy. $36: 6420-6432$.

17. Pavan MV, Balamurugan K, Balamurugan P. (2020) Compressive test Fractured Surface analysis on PLA-Cu composite filament printed at different FDM conditions. InIOP Conference Series: Materials Science and Engineering, Vol. 988,pp. 012019. IOP Publishing

18. R.B. (1961) Squires Economic dispatch of generation directly from power system voltages and admittances, IEEE Trans. Power App. Syst. 79 (3):1235-1245. 
19. Robinson, J., \& Rahmat-Samii, Y. (2004). Particle swarm optimization in electromagnetics. IEEE Transactions Antennas Propagation, 52(2) :397-407.

20. Sampathkumar, A., Murugan, S., Ahmed, A., Elngar, Lalit Garg, Kanmani, R., Christy Jeba Malar, A. (2020) A Novel Scheme for an IoT-Based Weather Monitoring System Using a Wireless Sensor Network." In Integration of WSN and IoT for Smart Cities :181-191.

21. Sampathkumar, A., Maheswar, R., Pon Harshavardhanan, Murugan, S., Jayarajan, P., Sivasankaran, V. (2020) Majority Voting based Hybrid Ensemble Classification Approach for Predicting Parking Availability in Smart City based on IoT." In 2020 11th International Conference on Computing, Communication and Networking Technologies (ICCCNT) : 1-8.

22. Thompson, R. D. (2002). Atmospheric processes and systems, Routledge Chicago. 